\title{
Professores de Química em Formação Inicial: o que Pensam e Dizem sobre as Relações entre Meio Ambiente, Ciência, Tecnologia e Sociedade
}

\section{Chemistry Teachers in Initial Formation: What they Think and Say about the Relations between Environment, Science, Technology and Society}

\author{
Rodrigo Luz ${ }^{[1}$ Brasil \\ Eliane dos Santos Almeida ${ }^{\text {(1) }}$ Brasil \\ Elisangela Silva do Nascimento Brasil \\ Christiana Andréa Vianna Prudêncio ${ }^{-10}$ Brasil
}

Este artigo tem como objetivo investigar as compreensões de licenciandos em Química sobre as relações entre Meio Ambiente, Ciência, Tecnologia e Sociedade no sentido de subsidiar processos formativos a serem desenvolvidos no contexto do ensino de Ciências. Para tal, foram realizadas entrevistas semiestruturadas com alunos de uma universidade estadual, que expressaram a maneira como compreendem essas relações a partir de situações problemáticas e/ou controversas presentes na atualidade e recorrentes nas mídias sociais. As informações obtidas foram analisadas por meio da Análise Textual Discursiva que possibilitou o estabelecimento de três categorias principais: i) Ciência e Tecnologia: “Tudo depende de como eu uso?"; ii) É possível conservar e desenvolver? e; iii) A Ciência e a Tecnologia podem salvar o planeta? Dentre os resultados encontrados destacam-se: ausência de percepção e reconhecimento do processo de construção da Ciência-Tecnologia (CT); fuga da realidade objetiva e silenciamento/ocultamento da discussão acerca da base material capitalista; existência de concepções contraditórias e imprecisas a respeito da (não) neutralidade da CT; variedade de posicionamentos sobre a (in) conciliação entre conservação e desenvolvimento, quase sempre ligados à uma compreensão de Meio Ambiente próxima de natureza impactada e; uma visão otimista acerca das implicações sociais da CT e do papel das pessoas no encaminhamento e resolução dos problemas sociais. Além disso, de maneira geral, os licenciandos apresentam respostas pouco elaboradas, em que predominam visões reducionistas e focalistas que precisam ser problematizadas nos cursos de formação inicial de professores de Ciências.

Palavras-Chave: Educação em Ciências; Educação CTS; Educação Ambiental; Formação de professores de Ciências/Química. 
This article aims to investigate the understandings of undergraduates in Chemistry regarding the relationships between Environment, Science, Technology and Society, in order to support training processes to be developed in the context of science education. To this end, semi-structured interviews were conducted with students from a state university, who expressed the way they understand these relationships from problematic and/or controversial situations present today and trending in social media. The information obtained was analyzed through Discursive Textual Analysis, which paved the way for the establishment of three main categories: i) Science and Technology: "Does everything depend on how I use it?"; ii) Is it possible to conserve and develop? and; iii) Can science and technology save the planet? Among the results found are: lack of perception and recognition of the process of construction of Science-Technology (ST); escape from objective reality and silence/concealing of the discussion about the capitalist material base; existence of contradictory and inaccurate conceptions regarding the (non) neutrality of the ST; variety of positions about the (un) reconciliation between conservation and development, often linked to an understanding of environment that is close to impacted nature, and; an optimistic view of the social implications of ST and the role of people in addressing and solving social problems. In addition, undergraduates generally present poorly elaborated responses, whose prominent reductionist and narrow views need to be problematized in initial science teacher education courses.

Keywords: Science education; STS education; Environmental education; Science/ Chemistry teacher training.

\section{Introdução}

Atualmente o mundo está imerso em atividades científicas e tecnológicas e, dessa forma, quem não consegue compreender essas atividades para manipular seus produtos, quando possível o acesso, e tomar decisões em questões referentes a CT pode ficar exposto a situações de exclusão social. A dinâmica estrutural da sociedade tem conduzido à dominação de consciências para manutenção do status quo, conforme afirma Freire (1987), gerando um conjunto de barreiras que impedem a leitura crítica do mundo. Essas barreiras têm sido disseminadas em vários contextos, nos meios de comunicação, nos processos educacionais, nas políticas públicas desenvolvidas etc., funcionando como empecilhos à construção de práticas inovadoras voltadas a transformação das relações sociais, naturais, políticas e econômicas.

Diante desse contexto, é importante que os professores de Ciências aprendam a lidar com esses desafios, de modo a construir, juntamente com seus alunos, uma visão crítica das atividades científicas e tecnológicas. Contudo, a formação inicial de professores ainda não têm promovido processos educativos capazes de favorecer a construção de uma compreensão abrangente e ao mesmo tempo particular das diferentes dimensões da realidade, especificamente no que diz respeito a pouco incorporar aspectos da Educação 
CTS $^{1}$ (Ciência, Tecnologia e Sociedade) e de suas complexas dimensões constitutivas (Prudêncio, 2013).

Assim, muitos professores de Ciências têm contribuído para perpetuar a ideia da neutralidade científica, considerando a CT livres de valores ou intenções, recaindo nos mitos que conferem ao conhecimento científico-tecnológico um estatuto de superioridade e a capacidade de resolver todos os problemas da humanidade (Auler, \& Delizoicov, 2006). Nesse contexto, as aulas de Ciências têm apresentado visões deturpadas sobre a Ciência e a atividade dos cientistas, desconsiderando os processos históricos envolvidos na produção e reprodução dos resultados da Ciência e seu caráter coletivo e social (Gil Pérez, Montoro, Alís, Cachapuz, \& Praia, 2001; Latour, \& Woolgar, 1997). Dessa forma, o campo da Educação em Ciências carece de pesquisas que investiguem as concepções de professores em formação inicial sobre a Educação CTS, sobretudo, no contexto brasileiro (Firme, \& Amaral, 2008).

A formação inicial dos professores é o ponto crucial de intervenção educativa, pois esses profissionais precisam de uma formação adequada para atuar na Educação Básica, que se configura como um campo voltado à formação integral dos jovens e a sua inserção cidadã na sociedade (MEC, 2000). Tais professores podem não conseguir alcançar tal intento se forem formados numa perspectiva acrítica, que desconsidere as relações entre Ciência, Tecnologia, Sociedade e Meio Ambiente. É preciso desconstruir a visão de Ciência como se fosse produção individual de pessoas extraordinárias; a Tecnologia como mero produto da Ciência; a Sociedade como um agrupamento de pessoas homogêneas e o Meio Ambiente como se fosse apenas natureza impactada.

Isso se torna ainda mais necessário quando se evidencia a influência das concepções dos professores no processo de ensino e aprendizagem (Kist, \& Ferraz, 2010), tendo em vista que esses repercutem suas ideologias na formação dos estudantes, auxiliando-os a desenvolverem suas próprias representações sociais. De acordo com Reis, Rodrigues e Santos (2006) a compreensão dessas concepções é importante para entendermos como os sujeitos percebem a realidade e estão dispostos para agir nela, com base em determinados conhecimentos, crenças, mitos, comportamentos, interesses e contradições sociais.

No Brasil, as pesquisas que analisam de maneira integrada a relação entre Meio Ambiente e as demais dimensões presentes na tríade CTS são escassas, inclusive no âmbito das concepções e do imaginário social (Luz, 2019), o que justifica a necessidade de problematização dessas compreensões socioambientais à luz de referencial teórico

\footnotetext{
1 Apesar de essa pesquisa tratar sobre Meio Ambiente de maneira vinculada às demais dimensões presentes na tríade CTS, optamos em não utilizar a denominação Educação CTSA (Ciência, Tecnologia, Sociedade e Ambiente) pelo fato de ainda não haver um consenso entre os pesquisadores da área com relação aos sentidos atribuídos a essa nomenclatura, persistindo muitas vezes reducionismos e simplismos no tratamento da questão ambiental (Luz, Araújo-Queiroz, \& Prudêncio, 2019). Além disso, ainda não temos certeza sobre em quais aspectos a Educação CTSA se diferenciaria da Educação CTS (esta desde sua gênese apresenta preocupação com a dimensão ambiental); se aquela se constituiria num novo campo de estudos ou se caracterizaria como um desdobramento de estudos e reflexões realizados no campo habitual.
} 
pertinente, visto que podem constituir barreiras para a transformação social.

Diante do exposto, a incorporação de pressupostos da Educação CTS nos currículos dos cursos de licenciatura em Ciências é de suma importância para uma abordagem referenciada e socialmente pertinente da CT e de sua relação com as dimensões sociais e naturais no âmbito da formação de professores e estudantes na Educação Básica. Assim, neste trabalho temos como objetivo investigar as compreensões de licenciandos em Química sobre as relações entre Meio Ambiente, Ciência, Tecnologia e Sociedade no sentido de subsidiar processos formativos a serem desenvolvidos no contexto do ensino de Ciências.

\section{Educação CTS e ensino de Ciências: algumas reflexões}

A Educação CTS tem contribuído para a Educação em Ciências, por ser um campo de estudos que busca, dentre outras coisas, desmistificar a ideia positivista da Ciência por meio da abordagem da dimensão social da CT. Para Fourez (1995), os cientistas são seres humanos e como tais possuem valores, crenças, vieses e pressupostos que não são simplesmente "apagados" quando iniciam sua prática científica, mas que pelo contrário, os acompanham, pois não podem desvincular-se da natureza humana.

O movimento CTS surge na década de 1960 em países americanos e europeus, reivindicando uma maior participação social nos processos decisórios que envolvem a Ciência e a Tecnologia e a construção de uma consciência pública sobre os riscos que o desenvolvimento descontrolado da CT poderia trazer para a sociedade e a natureza. Houve uma compreensão por parte dos sujeitos de que o desenvolvimento científicotecnológico nem sempre trazia benefícios para a humanidade, sendo responsável por uma série de problemas socioambientais que afetavam (e ainda afetam) a qualidade de vida das pessoas e a dinâmica dos diferentes ecossistemas presente na Terra, colocando em risco a própria existência humana, como no caso do bombardeamento atômico realizado pelos Estados Unidos em cidades do Japão durante a segunda guerra mundial e, mais recentemente, o rompimento da barragem de rejeitos da empresa mineradora Vale na cidade de Brumadinho em Minas Gerais no Brasil.

Paralela a essas reivindicações sociais marcantes na América do Norte, no contexto europeu circulavam discussões nas universidades e centros de pesquisa sobre a natureza da Ciência e seu caráter social (Strieder, 2012). A convergência desses esforços de pesquisa atrelada à prática social mobilizadora nas diferentes instâncias sociais, deu condição para que ao longo do tempo fosse construído um campo de estudos sobre Ciência, Tecnologia e Sociedade, constituído por um conjunto de pressupostos, teorias e metodologias que passou a ser discutido no âmbito das políticas públicas, na pesquisa acadêmica e na Educação em Ciências.

No contexto da educação, essas ideias alcançaram vários países, adquirindo repercussão no Brasil na década de 1990, quando alguns programas de pós-graduação da área de Educação em Ciências começaram a desenvolver as primeiras pesquisas sobre essa temática (Santos, \& Schnetzler, 2010). Atualmente, a Educação CTS apresenta- 
se como um campo de saber consolidado no Brasil, cuja produção científica tem aumentando significativamente ao longo dos anos, nos eventos e periódicos da área e também em cursos de pós-graduação (Freitas, \& Ghedin, 2015; Santos, \& Schnetzler, 2010). A Educação CTS também tem alcançado a dimensão curricular, visando a reestruturação de currículos a serem concebidos e executados a partir de temáticas ou problemas sociocientíficos.

Um dos pressupostos básicos da Educação CTS é a ideia de que os processos educativos não devem ter como ponto de partida conceitos científicos a serem mecanicamente incorporados pelos estudantes, mas a abordagem de temas de alcance local, regional e/ou global de modo a problematizar a dimensão social e contemplar os conteúdos da Ciência (Aikenhead, 1994; Santos, \& Schnetzler, 2010).

Para tornar a Educação CTS mais coerente com o contexto brasileiro, tem sido buscadas articulações com o Pensamento Latino-Americano em Ciência, Tecnologia e Sociedade (PLACTS) e com o Pensamento Educacional de Paulo Freire, ambos originados na década de 1960 na América Latina, visto que esses defendem o encaminhamento das demandas e necessidades latentes da realidade em que vivem os sujeitos e não a incorporação acrítica e subordinada de modelos provenientes de outros países (Auler, \& Delizoicov, 2011). Nessa perspectiva, o ensino de Ciências necessita envolver a investigação de temas ou problemas que sintetizem contradições sociais presentes no contexto de vida dos sujeitos, com o objetivo de problematizar a realidade e possibilitar a reflexão e ação para a superação das barreiras que se interpõem entre práticas conservadoras e transformadoras da sociedade.

A Educação CTS representa um movimento de contracorrente, caracterizado pelo embate intencional contra a estrutura social vigente, em que predomina a cisão entre concepção e execução de currículos escolares engessados e ditados sobre os moldes tradicionais. Nesse contexto social, poucos pensam e muitos executam, sem refletirem sobre o que de fato estão a fazer, contribuindo para a manutenção da ordem social vigente e para o encaminhamento de propostas e objetivos particulares que foram tornados universais, como se correspondessem a todos, ao passo que criam falsas necessidades e demandas sociais (Auler, 2018).

Ainda no contexto educacional, Auler e Delizoicov (2006) ressaltam a necessidade da superação dos mitos ligados à neutralidade científica, quais sejam: a superioridade do modelo de decisões tecnocráticas, em que se acredita que somente os especialistas podem tomar decisões sobre assuntos ligados a Ciência e a Tecnologia; a perspectiva salvacionista da Ciência, que parte da ideia de que a Ciência e a Tecnologia podem resolver todos os problemas da humanidade e; o determinismo tecnológico, em que persiste a ideia da Tecnologia como a determinante das relações sociais, ou seja, esta é autônoma e determina a vida e o modo de viver das pessoas que devem aceitar o fluxo e a ordem das coisas. Em concordância com Auler e Delizoicov (2006) compreendemos que a superação desses mitos pode possibilitar uma maior participação social nas atividades da Ciência e da Tecnologia, podendo romper com a cultura do silêncio, em direção à 
tomada de consciência da realidade existencial.

No contexto brasileiro, a Educação CTS contempla uma diversidade de concepções e práticas, devido a tríade em si mesma comportar uma variedade de interpretações acerca do que seriam suas dimensões constitutivas e as relações existentes entre elas (Roso, \& Auler, 2016; Strieder, 2012). Considerando essa diversidade de abordagens, Strieder (2012) afirma que o campo da Educação CTS mostra-se polissêmico no Brasil, existindo desde abordagens CTS de caráter mais ingênuo, relacionadas apenas ao reconhecimento da presença da Ciência e da Tecnologia no mundo, até àquelas compreensões consideradas mais críticas, em que há o entendimento da atividade científico-tecnológica como construção humana, que possui limitações, sendo portanto insuficiente para encaminhar os problemas reais que afligem a sociedade.

Embora existam diferentes compreensões sobre Ciência, Tecnologia, Sociedade e Meio Ambiente, nessa pesquisa, partilhamos da compreensão de que a Ciência é uma produção humana e, portanto, palco de disputas, interesses e valores; constituída por um conjunto de conhecimentos que busca explicar o mundo sensível de maneira sistematizada, mas que não se configura como uma verdade absoluta e acabada. A Tecnologia, assim como a Ciência, é um constructo social caracterizado por dimensões organizacionais, culturais e técnicas capazes de modificar a vida das pessoas, todavia não se resume a uma mera aplicação do conhecimento científico, podendo inclusive limitar ou potencializar esse conhecimento (Santos, \& Mortimer, 2002). Entendemos ainda que a Sociedade constitui o espaço formado por pessoas heterogêneas, com diferentes crenças, valores, atitudes e posições sociais, onde as relações sociais acontecem; e que abarca a atividade científica e tecnológica, produzida historicamente pelos sujeitos que a compõem, seja de maneira democrática e colaborativa ou totalitária e coercitiva. $\mathrm{O}$ Meio Ambiente, por sua vez, longe de ser reduzido apenas à natureza, representa o lugar constituído por relações ecológicas, sociais, culturais, políticas, históricas, científicas e tecnológicas que, integradas umas às outras, sintetizam a existência do mundo e das possibilidades criadoras (Luz, Araújo-Queiroz, \& Prudêncio, 2019).

No contexto da formação de professores de Ciências é necessário que se discutam as relações entre Ciência, Tecnologia, Sociedade e Meio Ambiente para evitar uma compreensão reducionista das questões socioambientais e potencializar a construção de novos horizontes, em que Ciência e Tecnologia possam ser pensadas e utilizadas para a superação de demandas e necessidades sociais, na direção da construção de uma sociedade inerentemente justa e igualitária. Assim, é necessário que as discussões sobre CTS para o ensino de Ciências sejam abordadas tanto no âmbito da Educação Básica quanto dos estudos superiores (Santos, 2007).

Apesar do surgimento de cursos sobre CTS voltados para a formação de professores, o ensino de Ciências na maioria das escolas ainda vem sendo trabalhado de forma descontextualizada (Santos, 2007). Atualmente muitos professores apresentam resistência para desenvolver aulas pautadas na Educação CTS, devido aos inúmeros obstáculos e desafios presentes nas escolas e a falta de preparo para lidar com temas 
sociocientíficos complexos. Assim, Delizoicov (2004) ressalta a necessidade de se avaliar as contribuições da formação continuada na modificação da prática docente e recomenda que os cursos de formação considerem as condições de atuação do professor no contexto escolar. Além disso, o referido autor aponta que há poucas discussões entre os pesquisadores da área de Educação em Ciências sobre os impactos das próprias pesquisas. Dessa forma, para que a Educação CTS seja efetivada, principalmente na Educação Básica é preciso que as pesquisas sobre CTS busquem uma maior articulação com os processos de formação de professores de Ciências, tanto inicial quanto continuada. Também se faz necessário fortalecer a relação universidade-escola para que haja um compartilhamento de experiências, saberes e práticas capazes de ressignificar a compreensão e a ação dos professores sobre os temas e conteúdos que lecionam.

\section{O caminho metodológico da pesquisa}

Este trabalho faz parte de uma pesquisa mais ampla ${ }^{2}$ que investiga como os pressupostos da Educação Ambiental e da Educação CTS estão sendo discutidos em cursos de licenciatura em Ciências nas áreas de Química, Física e Biologia no contexto da Universidade Estadual de Santa Cruz, localizada no município de Ilhéus/Bahia. Neste artigo, entrevistamos seis estudantes do último semestre do curso de Licenciatura em Química, no segundo semestre letivo do ano de 2017. A escolha dos sujeitos justifica-se pelo fato de esses licenciandos já estarem inseridos nas discussões acadêmicas referentes à docência, visto que cursaram quase todas as disciplinas pedagógicas e específicas, inclusive os estágios supervisionados e já vivenciaram a realidade do ensino de Química na Educação Básica. Para manter o anonimato dos sujeitos, estes foram identificados como LQ1, LQ2, LQ3, LQn..., e assim sucessivamente, em que o código $L Q$ significa Licenciando em Química.

Foram realizadas entrevistas semiestruturadas com os professores em formação inicial com o objetivo de compreender suas concepções sobre Meio Ambiente, Ciência, Tecnologia e Sociedade, bem como a maneira como esses conseguiam explorar as relações entre essas dimensões no contexto do ensino de Ciências. A entrevista, composta por questões abertas, foi realizada de maneira individual com cada sujeito e durou cerca de 40 minutos. Todas as entrevistas foram gravadas em áudio e posteriormente transcritas na íntegra. A entrevista consistiu na apresentação de três situações ${ }^{3}$ polêmicas e/ou controversas relacionadas a temáticas contemporâneas recorrentes nas mídias sociais. Os temas presentes nas situações foram os seguintes: Conservação e Desenvolvimento, Problemas Socioambientais e Produção/utilização da CT. Tais temas foram escolhidos porque envolvem diferentes opiniões acerca da CT na contemporaneidade, exigindo a reflexão, o diálogo, o compartilhamento de informações e a tomada de posição frente a

2 Pesquisa aprovada pelo Comitê de Ética com número do Certificado de Apresentação de Apreciação Ética (CAAE): 72195317.7.0000.5526

3 Para permitir uma leitura mais fluida e agradável do texto, as situações presentes no roteiro de entrevista relativas a cada temática serão apresentadas em tópico pertinente na seção de resultados. 
diferentes possibilidades de encaminhamento da questão em debate.

As entrevistas foram analisadas por meio da Análise Textual Discursiva (ATD), que de acordo com Moraes e Galiazzi (2011), é composta por três partes fundamentais: 1) Unitarização: desconstrução do texto fragmentando-o em unidades de significado. Essa etapa consistiu na fragmentação das entrevistas transcritas, para obtenção de dados pertinentes ao objetivo da pesquisa. Essas unidades de significado foram destacadas nos excertos que compõem a seção de resultados desse artigo. 2) Categorização: as unidades de significado foram relacionadas e agrupadas em categorias semelhantes que necessitam ser homogêneas em sua individualidade e, além disso, fazer sentido para os sujeitos da pesquisa. Nesta pesquisa foram obtidas três categorias, definidas a priori, que consistiram em: i) Ciência e Tecnologia: “Tudo depende de como eu uso?”; ii) É possível conservar e desenvolver?; e iii) A Ciência e a Tecnologia podem salvar o planeta?; 3) Comunicação: as categorias produzidas possibilitaram uma nova compreensão das partes e do todo, de modo que foram escritos textos argumentativos referentes as percepções e entendimentos dos licenciandos sobre as relações entre Meio Ambiente, Ciência, Tecnologia e Sociedade.

$\mathrm{Na}$ busca pela confiabilidade das análises realizadas, as falas dos licenciandos foram divididas de maneira equivalente entre os autores dessa pesquisa, que analisaram os excertos agrupando-os em categorias capazes de expressar os sentidos evocados. Em seguida, cada categoria foi validada pela análise subsequente de outro autor, que observou novamente as partes unitarizadas no texto pelo autor anterior, buscando remetê-las a categoria utilizada e retornando sempre que necessário ao corpus das entrevistas para maior compreensão do objeto investigado. O procedimento se repetiu até que todos os autores tivessem a oportunidade de analisar todas as categorias presentes na pesquisa, inserindo suas contribuições e ao mesmo tempo se submetendo a avaliação dos pares, no sentido de alcançar uma coerência interna.

\section{Ciência e Tecnologia: "tudo depende de como eu uso?"}

Nessa categoria buscamos identificar as concepções dos licenciandos em Química sobre Ciência, Tecnologia e suas implicações sociais. Para tal, solicitamos que se posicionassem sobre a seguinte situação: "A Ciência e a Tecnologia em si mesmas não trazem prejuízos. Elas não são boas nem más, depende da forma como são utilizadas”.

Em análise às respostas sobre a situação mencionada, identificamos que todos os licenciandos parecem compreender a Ciência e a Tecnologia como neutras e, portanto, livres de interesses e valores, sendo que suas implicações sociais dependem da forma como são utilizadas pela sociedade, conforme evidenciam algumas falas a seguir:

Quem está usando esses meios é quem vai definir se é uma coisa boa ou não, se vai ser para o bem ou para o mal. Não dá para dizer que os avanços tecnológicos são uma coisa ruim. Também não dá para dizer que uma pesquisa com células-tronco é uma coisa ruim, está entendendo? (LQ3).

4 A frase baseia-se em Auler e Delizoicov (2006). 
[...] você pegar o conhecimento da Ciência e transformar para questões bélicas é uma opção sua. Você está fazendo a Ciência má na visão da sociedade, mas não foi a Ciência que foi má, é a sociedade que quis utilizar para os fins que não seriam bons. [...] é a forma como a sociedade utiliza o que a Ciência e a Tecnologia produzem (LQ5).

[...] não trazem [malefício] a não ser que sejam utilizadas para trazer prejuízos. Ela [Ciência] em si não deveria trazer prejuízo algum, deveria trazer conhecimento e avanços, mas a má utilização acaba levando ao prejuízo também à sociedade (LQ6).

De acordo com os relatos dos licenciandos, as implicações sociais da CT dependem exclusivamente de como os indivíduos utilizam os seus produtos no dia a dia. Essa compreensão sustenta uma concepção mitificada e ingênua da CT, pois desconsidera os valores e interesses que têm norteado seu processo de produção, negando o fato de que a CT são uma construção humana, influenciada pela sociedade, especificamente pelos interesses da classe hegemônica (Delizoicov, \& Auler, 2011). Ciência e Tecnologia também influenciam significativamente no rumo da sociedade, proporcionando tanto melhoria de vida, geralmente de forma não equitativa, quanto sérios problemas ambientais e sociais. Strieder (2012) e Auler $(2002,2018)$ defendem que ao se enfatizar os aspectos positivos e negativos do uso da CT, sem discutir seu processo de produção, está-se concebendo as atividades da CT de maneira dissociada dos sujeitos que as produzem, responsabilizando apenas as pessoas que utilizam e consomem os produtos gerados, deixando o cerne do problema intocável.

Para desmistificar essa concepção de neutralidade da CT é preciso discutir os conflitos ideológicos e os interesses envolvidos no seu processo de produção, o que pode contribuir para a democratização da participação nos processos decisórios, visto que as decisões que envolvem questões sobre CT, geralmente, são resolvidas por meio de escolhas tecnocráticas (Auler, \& Delizoicov, 2006). Ainda de acordo com os autores, uma compreensão acrítica sobre CT pode constituir barreiras à compreensão crítica da realidade, visto que a sociedade atual tem sua dinâmica imersa nas atividades científicas e tecnológicas.

Ressaltamos que, no decorrer da entrevista, o pesquisador foi problematizando as respostas dos licenciandos e eles começaram a refletir, chegando a mencionar, algumas vezes de forma confusa, a influência da sociedade nas atividades científicas e tecnológicas, os erros e interesses relacionados a essas atividades, conforme expressam as falas a seguir:

[...] nem sempre a Ciência, os cientistas vão ter culpa, porque muitas vezes eles foram solicitados para fazer aquilo ali e fizeram na perspectiva que iria dar certo, só que o problema que eles têm a noção que poderia dar errado [...]. Os cientistas, eles podem ter sido obrigados a fazer, no entanto, eles têm o conhecimento sobre aquilo, que poderia dar errado. Eles levariam a culpa, mas por eles estarem sendo pressionados pela sociedade, a sociedade também leva a culpa, aí tudo é culpado (LQ5).

[...] mas também entra essa questão, por exemplo, aqui, esse porto, é Tecnologia, 
é Ciência, tentando melhorar as condições financeiras do país, que a intenção é financeira, totalmente ruim, mas eles [cientistas] estão pensando a sociedade, estão pensando a sociedade civil, eu não sei, nem é civil, o povo não tá nem aí. O governo, ele quer algo, ele quer algo mais econômico para o país, no entanto, não está pensando muito ambientalmente que vai influenciar aquilo ali (LQ5).

Como assim, alguém produziu e outras pessoas usaram, a pessoa que utilizou, utiliza isso aqui pelas regras de quem produziu. $\mathbf{O}$ erro foi de quem produziu, porque passou as regras de forma errada, mas se a pessoa que utilizou, utilizou usando regras que ela mesmo definiu, aí o problema é de quem utilizou, talvez, porque aí já é uma questão ética e moral. Você sabia do que era permitido e foi utilizar de formas que não são as formas indicadas. Eu acredito que pode acontecer de ser [a culpa] tanto de quem produziu quanto de quem utilizou, depende de como foi utilizada de como foi feito isso, ao processo, sabe (LQ6).

Podemos perceber na primeira fala de LQ5 a visão da Ciência e dos cientistas como possuidores de conhecimentos necessários para conceber o que é certo ou errado, de fazer as melhores escolhas para a sociedade. Ainda para este licenciando, a sociedade tem influenciado negativamente a atividade científica e tecnológica por meio de pressões sociais, gerando problemas, como erros no processo de produção da CT. Entretanto, sabemos que nem sempre os cientistas estão investigando demandas sociais da região, pelo contrário, muitas vezes as demandas investigadas são externas às reais necessidades da população, que ainda permanece alijada dos processos de tomada de decisão, exercendo sua participação apenas no nível da informação sobre os produtos da Ciência e não sobre sua produção (Auler, 2018; Auler, \& Delizoicov, 2015; Strieder, \& Kawamura, 2017).

LQ5 ao buscar relacionar CT a seu contexto de vida, consegue perceber que é o interesse econômico que tem guiado a construção de um porto no município de Ilhéus/ Bahia, em detrimento do bem-estar do Meio Ambiente, visto como natureza impactada. Já LQ6 não consegue perceber os reais interesses envolvidos na produção da CT, pois para ele quando há alguma consequência socioambiental provocada por erros no processo de produção de determinado produto, a culpa é do cientista que se equivocou e que não teve necessariamente a intenção de promover tal situação. Em algumas falas, o cientista é visto como o detentor do conhecimento, o profissional isento e ideal para tomar decisões sobre CT, no sentido de informar a sociedade sobre a maneira mais correta de agir.

Se levada ao extremo, essa compreensão pode levar ao endosso do mito das decisões tecnocráticas (Auler, 2002) quando há o entendimento de que os cientistas devem decidir sobre determinadas questões, pois possuem os conhecimentos adequados, desconsiderando o fato de que cidadãos também podem (e devem) participar da elaboração e definição dessas decisões. Nessa perspectiva “o expert (especialista/técnico) pode solucionar os problemas sociais de um modo eficiente e ideologicamente neutro" (Auler, \& Delizoicov, 2006, p. 341), ao passo que a participação social não é reconhecida. 
É relevante destacar que, mesmo de forma ingênua, nas falas de LQ5 e LQ6 percebemos o reconhecimento de que a Ciência é feita por pessoas que tem limitações, podendo estar sujeita a erros e a influências sociais. Nessa perspectiva, para Santos e Mortimer (2002) "a Ciência não é uma atividade neutra e o seu desenvolvimento está diretamente imbricado com os aspectos sociais, políticos, econômicos, culturais e ambientais" (p. 96). Essa compreensão, mesmo que ainda num nível de criticidade pouco elaborado, destoa de discursos anteriores, em que a neutralidade científica era reforçada pelos sujeitos ao dissociarem as pessoas dos processos de construção da CT, considerando essas dimensões como autônomas e livre de valores ou interesses.

Essa contradição presente nos discursos dos licenciandos também está presente no estudo de Deconto, Cavalcanti e Ostermann (2016), que identificam respostas confusas e ambíguas a respeito das relações CTS. De acordo com os autores, esses conflitos presentes no mesmo sujeito apresentam distintas intensidades em seus discursos e sinalizam para "um movimento de "vai e vem" de vozes caracterizadas por diferentes níveis - vozes estas que algumas vezes se complementam, mas que, via de regra, chocamse, não se harmonizam, são contraditórias" (p. 114). Auler e Delizoicov (2006) afirmam que as contradições estão relacionadas à uma compreensão imprecisa e confusa sobre a neutralidade da CT, em que não se sabe ao certo se essas dimensões seriam autônomas e separadas da subjetividade humana ou totalmente dependentes dessa.

Diante das compreensões dos licenciandos sobre CT e suas implicações sociais, é necessário fazer algumas reflexões, tais como: os cientistas são os mais adequados para tomar decisões em questões que afetam a sociedade? Os conhecimentos científicos são suficientes para encaminhar os problemas sociais? Quem tem conseguido de fato exercer influência sobre as atividades da CT, a sociedade como um todo ou algumas pessoas economicamente favorecidas? Os cientistas conseguem ter total controle sobre os conhecimentos produzidos e disseminados na sociedade?

Strieder, Bravo-Torija e Gil-Quilez (2017) sinalizam que as discussões sobre as implicações sociais de CT são tratadas com pouca criticidade e de forma superficial no âmbito da sala de aula e nos processos formativos de professores. As autoras defendem a necessidade de se discutir as insuficiências da Ciência para a compreensão e transformação da realidade, devido a seus riscos e incertezas; as adequações sociais das tecnologias às necessidades regionais em virtude da CT serem direcionadas pelos interesses capitalistas em detrimento das demandas sociais e; a participação social no âmbito das esferas políticas, na definição de seus objetivos, meios para alcançá-los e maneiras para controlar sua implementação.

\section{É possível conservar e desenvolver?}

Para compreender as ideias e posicionamentos dos licenciandos sobre as possíveis vinculações entre Meio Ambiente, Ciência, Tecnologia e Sociedade, especificamente sobre a relação entre Conservação e Desenvolvimento (CD), solicitamos que opinassem a respeito da seguinte afirmação: "Conservação dos recursos naturais e desenvolvimento 
científico-tecnológico são coisas incompatíveis em umasociedade. Logo, Ciência e Tecnologia são dimensões que prejudicam o Meio Ambiente e são externas a ele". A reflexão dos licenciandos em torno dessa situação levou ao estabelecimento de três subcategorias, quais sejam:

a) Conciliabilidade entre $\mathrm{CD}$ : prevalece a ideia de que é possível conservar e desenvolver, considerando relações impactantes e/ou estratégias amenizadoras desses impactos na natureza ou mesmo desconsiderando qualquer tipo de riscos, efeitos, consequências ou possibilidades de transformação social.

b) Inconciliabilidade entre CD: nesse caso, não é possível conservar e desenvolver, uma vez que uma dimensão sempre implicará na anulação da outra, considerando, sobretudo, as relações impactantes da atividade antrópica sobre a natureza.

c) (In) Conciliabilidade entre CD: compreensão que considera possíveis ambas as condições, estabelecendo um estado de dependência a partir das disposições humanas que podem agir dissociando essas dimensões ou considerando-as de maneira integrada.

Nas três compreensões apresentadas pelos licenciandos sobre a relação entre Conservação e Desenvolvimento, giram outros dois tipos de relação que, em maior ou menor grau, podem permear cada uma dessas compreensões, são elas: relações antagônicas entre $C D$, em que persiste a ideia de que Conservação e Desenvolvimento são dimensões que atuam em sentido contrário e; relações equivalentes entre $C D$, em que reside a ideia de que Conservação e Desenvolvimento não são opostos entre si, atuando no mesmo sentido. Essas duas possibilidades de relações podem ainda ser do tipo dependente, em que apenas uma das dimensões apresentadas só existe em decorrência da outra; ou do tipo interdependente, em que ambas as dimensões exibem dependência mútua.

No âmbito da primeira subcategoria Conciliabilidade entre $C D$, situam-se as reflexões dos sujeitos LQ1, LQ2 e LQ3:

$\mathrm{Eu}$ acho que são coisas que dá para caminhar juntas. Lógico que em algum momento a gente vai ter que pender numa força maior na conservação dos recursos em contrapartida da Ciência, assim como em determinados momentos a gente vai ter que ter a Ciência pesando mais sobre a conservação dos recursos. Porque se a gente for pensar em conservação dos recursos e desenvolvimento da Ciência, digamos, se a Ciência desenvolvesse mais, se a gente tivesse que extrair mais recurso para poder extrair a fome seria uma coisa necessária ou então seria uma coisa plausível, mas em contrapartida a gente tem outras coisas. Se a gente extrair demais madeira, por mais que seja necessário para a evolução científica, a gente precisa ter uma conservação, porque se não vai ter a extinção daquele recurso (LQ1).

Você pode usar muito bem a Ciência e a Tecnologia, conservando os recursos naturais, porque recursos naturais uma hora acabam. Conservando esses recursos de uma forma que degrada o mínimo possível o ambiente, então é uma forma de você conservar a Sociedade, o Meio Ambiente, usando, desenvolvendo e criando novas 
ciências e novas tecnologias. Você pode usar Ciência e Tecnologia para a preservação do Meio Ambiente. Tem uma bugiganga, não sei o que é aquilo, que um cara fez que ele pega o chorume do lixão e transforma em água limpa. Você está entendendo? (LQ3).

Percebemos no excerto, que LQ1 acredita que Conservação e Desenvolvimento possam coexistir, entretanto, não desconsidera a existência de dualidade/oposição entre essas dimensões. Embora ele apresente a compreensão de que o desenvolvimento da Ciência implica a retirada de recursos e que, portanto, em alguns momentos a conservação será mais enfatizada que o desenvolvimento e vice-versa, entende que a Ciência pode contribuir para a conservação e esta pode estar atrelada ao desenvolvimento. Também compreende que existem problemas de relevância social, como a fome, em que a retirada de recursos da natureza seria uma ação justificável pela finalidade pretendida, ou seja, por se tratar de uma causa nobre.

De maneira semelhante, o sujeito LQ3, entende a Ciência e a Tecnologia como um meio para a conservação ambiental, partindo do entendimento de que os recursos naturais podem acabar. O mesmo apresenta uma compreensão limitada do Meio Ambiente, percebendo-o apenas como natureza a ser impactada minimamente nesse processo de intermediação científico-tecnológica. Entretanto, esse aspecto que anuncia a existência, mesmo que ínfima de algum risco à natureza, é ocultado pela crença de que o desenvolvimento científico-tecnológico pode contribuir para a conservação ambiental, levando o licenciando a desconsiderar as implicações desse desenvolvimento sob o ponto de vista da sociedade capitalista em que vivemos. Evidenciamos que o mesmo fala de um lugar externo à realidade imediata e objetiva vivenciada pelos sujeitos nesse momento histórico, projetando-se muito mais para o que poderia ser ao invés do que de fato é ou tem ocorrido preponderantemente nas diferentes sociedades. Talvez isso ocorra devido ao seu olhar otimista para a questão da CD, em que se destaca a proposição de construção de novas tecnologias e novas ciências que possam estar atreladas à conservação da natureza, como se aquelas que temos atualmente não estivessem servindo a esse ideal.

Nesse sentido, tanto LQ1 quanto LQ3 apresentam a ideia de que CD expressa relações antagônicas interdependentes, porque enquanto uma dimensão existe a outra é diminuída ou enfraquecida, mas aquela depende desta para continuar e vice-versa.

No âmbito da segunda subcategoria Inconciliabilidade entre CD situamos apenas o posicionamento de LQ5:

A gente está, eu estou utilizando algo que vai ter um fim um dia, então está de certa forma fazendo um "boom" na Tecnologia e gastando aquilo que um dia vai acabar, ou seja, destruindo com o meio. Então é complicado, só que hoje a sociedade tem a visão que precisa de muitas coisas, precisa do desenvolvimento científico para sobreviver, só que as custas da utilização do que o mundo tem aí. E uma hora vai acabar algumas coisas e aí lascou-se. [...]. É complicado dizer que Ciência e Tecnologia prejudicam o Meio Ambiente, mas de certa forma sim. Não vejo como uma culpa da Ciência e Tecnologia somente, mas é uma culpa social, a gente, a sociedade quer assim e a Ciência e a Tecnologia tentam responder e acabam utilizando aquilo que o meio tem, só que eu não sei até que ponto elas têm lidado com essa questão de que uma hora os recursos 
que estão utilizando vão ter um fim, então a Ciência e a Tecnologia prejudicariam o meio (LQ5).

Como expresso no excerto, LQ5 entende que o desenvolvimento científicotecnológico implica na destruição da natureza, uma vez que esse processo tem consumido os recursos para satisfazer necessidades e anseios dos sujeitos. Em sua compreensão, tais recursos são finitos e esse fim terá muitas consequências. O mesmo ainda admite que a Ciência e a Tecnologia podem trazer prejuízos para o Meio Ambiente, mas condiciona essa ação à Sociedade, ou seja, são as pessoas que precisam dessas dimensões que são construídas em resposta a essas demandas, tentando respondê-las. Não reconhece, portanto, a lógica da atividade científica que predominantemente tem sido pensada para favorecer interesses alheios às reais necessidades da população, transmitindo valores e visões de mundo externos à realidade vivenciada, enquanto nossas demandas reais são negligenciadas (Auler, \& Delizoicov, 2015). Nesse sentido, nos parece que o licenciando entende que CD expressam relações antagônicas dependentes, mas que essa dependência em sua concepção só se expressa no segundo caso, uma vez que o mesmo não considera qualquer possibilidade de o desenvolvimento científico-tecnológico atuar em favor da conservação da natureza.

No âmbito da terceira subcategoria, (In) Conciliabilidade entre CD situamos as compreensões de LQ4 e LQ6. Trazemos como exemplo a reflexão formulada por eles, expressas nas seguintes falas:

Eu discordo, porque são as pessoas que fazem isso, não a Ciência e a Tecnologia. Então vai depender de como a pessoa utiliza mesmo e os conhecimentos na utilização. Também tem aquela questão do descarte, saber colocar no lugar certo. [...]. Eu acho que [Conservação e Desenvolvimento] são incompatíveis até certo ponto, porque tem algumas coisas que se renovam outras não, e também a velocidade que se renovam. Se conseguir utilizar de uma forma correta que não cause problemas ao Meio Ambiente e também não gere lixo, a quantidade que consiga trabalhar com esse lixo para não atacar o Meio Ambiente, também é possível (LQ4).

Conservação quer dizer que não vai mexer em recursos naturais para desenvolver a Tecnologia, se for assim são incompatíveis, porque geralmente a gente precisa, né, extrair algo da parte da natureza, essas coisas para a gente avançar na Tecnologia, se for assim é incompatível. Mas se estiver falando do geral, tipo "ah fui na natureza utilizei tal coisa, mas eu estou utilizando isso para poder melhorar aquele próprio ambiente, aquele próprio espaço", aí talvez não. Então acho que tem duas respostas, depende de qual ponto de vista. Pode ser e pode não ser, depende como acontece, se você vai lá só retirar, extrair, extrair e não faz nada com aquilo para melhorar, aí são incompatíveis, mais se você vai lá e tenta utilizar da melhor forma, mesmo que você não esteja conservando, porque você vai acabar tendo que retirar, mas você está utilizando isso para melhorar, para ampliar, para manter, talvez seja compatível (LQ6).

Em ambas as falas é expressa a ideia da possibilidade de conciliação ou não entre CD, pressupondo-se que para acontecer uma coisa ou outra existe a dependência 
de predisposições humanas, o que revela relações antagônicas de (inter) dependência entre $C D$. Em nenhum momento nas falas, percebe-se a vinculação dessas disposições humanas a um contexto sociocultural determinado e historicamente situado. Assim, para haver a conciliação, tudo dependeria da maneira como as pessoas utilizam a Ciência e a Tecnologia, enquanto que essas dimensões seriam incompatíveis se as pessoas utilizassem de maneira a satisfazer apenas suas vontades e necessidades sem a preocupação com a melhoria do Meio Ambiente, ainda entendido pelos licenciandos como natureza a ser impactada ou conservada pela Ciência e pela Tecnologia. A ideia do Meio Ambiente como natureza impactada pela ação humana, também foi encontrada em trabalhos anteriores realizados com diferentes sujeitos, fato que reforça a necessidade de problematização dessa compreensão socioambiental (Luz, 2016; Luz, et al., 2017; Luz, Prudêncio, \& Caiafa, 2018; Luz, Araújo-Queiroz, \& Prudêncio, 2019).

Chama a atenção, o fato de que LQ6 menciona a possibilidade de as intervenções científicas e tecnológicas serem utilizadas para melhorar o próprio ambiente, ou seja, em alguma medida os recursos naturais retirados retornariam para a natureza com o objetivo de conservá-la. Entretanto, não são apresentadas maneiras ou possíveis caminhos para tornar isso possível no contexto sociopolítico em que vivemos ou para além dessa forma de sociabilidade que predomina atualmente.

Assim, os licenciandos focam apenas nos produtos da CT, desconsiderando as intenções, interesses e privilégios existentes na atividade científica e no processo de construção e divulgação dos fatos científicos ao longo do tempo (Strieder, \& Kawamura, 2017). Tal movimento reflete uma concepção ingênua do desenvolvimento, uma vez que ao focarem nas consequências da atividade científico-tecnológica e, por conseguinte, nos impactos gerados por ela, eles terminam desconsiderando as causas que geram os problemas socioambientais enfrentados cotidianamente, o que poderia contribuir para realizar mudanças pontuais e momentâneas na realidade.

$\mathrm{Na}$ fala de LQ4 percebemos a restrição do Meio Ambiente à natureza e da questão ambiental às ações comportamentais individuais e reducionistas que visam mitigar efeitos e danos à natureza. Vemos também a ideia de neutralidade científica e de culpabilização individual ou coletiva pelos problemas gerados a partir da utilização da Ciência e da Tecnologia, ao passo que o processo de construção dessas dimensões sequer é reconhecido ou menos ainda questionado. Ao mesmo tempo, o licenciando reconhece que o desenvolvimento científico-tecnológico de uma sociedade trará consequências para o Meio Ambiente (natural), mas que é possível gerar menos impactos, respeitando o ciclo biofísico de regeneração dos recursos naturais, expressando, portanto, a existência de relações antagônicas interdependentes entre as dimensões colocadas em pauta.

Na fala de LQ6 percebemos que existe certa confusão no significado de conservação ambiental, pois ao contrário do que está exposto, esta admite a intervenção humana e a retirada de recursos naturais de maneira sustentável junto aos diferentes ecossistemas, ao contrário da preservação ambiental que pressupõe a ideia de uma natureza intocada, idílica e em perfeito equilíbrio, da qual o homem e suas construções não fazem parte 
(Silva, 2015). Essa compreensão que entende a relação ser humano-natureza como polos dicotômicos, em que o primeiro age sobre o segundo de maneira predatória e utilitarista, prejudica o entendimento de que o ser humano também faz parte da natureza e o fato de que a relação alienada que o mesmo tem desenvolvido com esta por meio do trabalho na atualidade reflete a forma de sociabilidade capitalista dominante nas diferentes sociedades presentes no mundo (Lessa, \& Tonet, 2008). Com relação a esse aspecto, em todas as falas analisadas a relação entre Conservação e Desenvolvimento foi tecida de maneira desvinculada de relações sociais mais amplas, em que não se vincula essas categorias ao modelo de sociabilidade capitalista vigente.

\section{A Ciência e a Tecnologia podem salvar o planeta?}

Nesta categoria, buscamos compreender as visões dos licenciandos em Química, sobre a capacidade de o desenvolvimento científico e tecnológico solucionar os problemas socioambientais que têm afligido nosso planeta, com base na perspectiva salvacionista da Ciência discutida por Auler (2002). Para tal, solicitamos que os licenciandos se posicionassem sobre a seguinte afirmação: “O desenvolvimento científico e tecnológico é capaz de resolver os problemas socioambientais do planeta (fome, miséria, desmatamento, poluição, aquecimento global etc.) levando ao bem-estar social”. As análises das respostas dos licenciandos estão organizadas em três subcategorias, quais sejam: a) CT podem minimizar os problemas socioambientais, mas são insuficientes para salvar o planeta: b) CT não promovem o bem-estar social e c) CT podem salvar a humanidade se forem redirecionadas.

a) A CT pode minimizar os problemas sociais, mas é insuficiente para salvar o planeta: nessa subcategoria os licenciandos entendem que o desenvolvimento científico e tecnológico ajuda a minimizar os problemas socioambientais, mas é insuficiente para salvar o planeta, pois a solução desses problemas perpassa também pela conscientização da população, conforme expressam as falas a seguir:

(CT) Não vai ser o salvador da pátria, mas ajuda bastante, porque não é só o desenvolvimento científico e tecnológico, as pessoas também têm que ter essa consciência. Porque não adianta eu ter todo um aparato, toda a ideia, descobrir como a soja ser multiplicada, se eu não tenho consciência de que eu tenho que mudar os meus hábitos também em prol disso tudo (LQ3).

(A Ciência) Sozinha não pode resolver, sozinha não, talvez porque acredito que não é só o desenvolvimento da Ciência, mas a conscientização também. Não adianta a Ciência se desenvolver se ela não vai ser bem utilizada, porque as pessoas não têm conscientização para utilizar, entendeu? E também, muitas vezes a Ciência, a Ciência tem isso de passar por altos e baixos. Hoje o método que é utilizado, é visto como algo muito bom, daqui a dez anos pode acontecer que não seja aquela verdade absoluta e não ser tão boa quanto parece [...] (LQ6).

Não é resolver é minimizar [...]. Aquecimento global mesmo, coisa que a gente trabalha 
bastante [...], então os meninos não têm essa ideia assim de que eles estão fazendo alguma coisa também que vai prejudicar. Eu acho assim, esse desenvolvimento todo científico-tecnológico pode minimizar isso. Porque se a pessoa tem um conhecimento já vai melhorar. Se eu sei que o aumento de carros está prejudicando por causa do combustível fóssil, que vai gerar os óxidos, que vai gerar outras coisas, eu vou ter um pensamento mais socioambiental para não fazer mais aquilo, para não sair mais. Mas isso depende do conhecimento da pessoa (LQ2).

Os licenciandos compreendem que os problemas socioambientais podem ser resolvidos a partir da relação conjunta entre CT e a população. Eles parecem compreender nesse contexto que CT não constituem uma dimensão autônoma e independente dos sujeitos, ou seja, só fazem sentido e adquirem função no âmbito das relações sociais. Essa compreensão está em consonância com as ideias de Pacey citado por Auler (2002), em que o autor defende que os problemas sociais como a poluição, não podem ser solucionados apenas por meio de soluções técnicas, visto que possuem uma componente social, logo "esperar por uma solução apenas técnica, que não inclua medidas sociais e culturais, é mover-se em um terreno ilusório" (p.107).

Em relação à conscientização da população, os licenciandos mencionam a necessidade do (re)conhecimento do problema, uso adequado da CT, aquisição de informações e desenvolvimento de ações pela população. Não percebemos respostas que se situam no âmbito da construção da atividade científica, que problematizem essa atividade, que debatam as razões para o desenvolvimento de determinadas pesquisas e não de outras, que discutam os interesses e valores característicos da CT. Diante das compreensões evidenciadas pelos licenciandos acerca da relação entre conhecimento, consciência e ação fazemos os seguintes questionamentos: a aquisição de informações e o reconhecimento do problema são suficientes para promover o engajamento dos educandos em prol da transformação social? Será que saber o que fazer é suficiente para o encaminhamento dos problemas, que seria necessário apenas o conhecimento sobre o tema? Atitudes individuais e/ou coletivas por parte da população são suficientes para resolver os problemas socioambientais? Quem são os culpados pelos impactos negativos da CT, quem produziu os produtos ou as pessoas que os utilizam? A conscientização diz respeito apenas à aquisição de saberes?

Para Freire (1987) a conscientização não para no reconhecimento da situação, mas prepara o povo para a prática social intencionalizada, para a luta contra os obstáculos à sua humanização, situando-se na dialética entre a reflexão e a ação sobre a situação existencial dos sujeitos. Atualmente, o desenvolvimento científico e tecnológico é considerado um obstáculo à humanização, visto que tem promovido a exclusão e a marginalização da população economicamente desfavorecida. Isso ocorre porque numa sociedade capitalista Ciência e Tecnologia são produzidas para alimentar o fluxo contínuo de mercadorias, a lógica da obsolescência programada, a destruição da natureza, o aviltamento das relações sociais e aumento da distância entre ricos e empobrecidos. Nesse contexto de insustentabilidade planetária, em que seres humanos 
são transformados em objetos dos sistemas de produção, as demandas sociais têm sido cada vez mais negligenciadas pelas agendas de pesquisa da CT, em virtude dos interesses da classe hegemônica (Auler, \& Delizoicov, 2015).

Em análise as falas dos licenciandos, evidenciamos que todos fazem menção a CT como benéficas para a humanidade. LQ2 cita os carros como uma das causas do aquecimento global, mas responsabiliza as pessoas pelo seu uso, sem apontar possibilidades da CT atuarem de forma mais ativa na solução deste problema. Na fala de LQ6 e LQ2, a crítica também recai nas pessoas que fazem uso dos produtos da Ciência, responsabilizando-as pelos impactos negativos, ao passo que os atores sociais que por meio da produção alimentam o consumo e, de maneira mais ampla, os mecanismos ideológicos capitalistas que balizam as múltiplas contradições e determinações sociais, permanecem silenciados, ocultos e ignorados.

Percebemos que os licenciandos não abordam sobre os interesses e valores que têm norteado as atividades científicas e tecnológicas, mesmo que um deles (LQ6) reconheça de maneira mais explícita que a Ciência não é uma verdade absoluta e cumulativa, que possui limitações em relação à previsão de seus resultados e que passa por períodos de continuidade e descontinuidade. Dessa forma, embora esteja evidente que os licenciandos, considerando a temática apresentada, se afastam de uma visão de Ciência e Tecnologia de natureza dogmática, neutra, acabada, individualista e cumulativa, percebemos que eles nutrem compreensões ingênuas que os aproximam de uma visão reducionista de CT, visto que focam mais nas consequências que a utilização dos produtos da Ciência pode gerar para as pessoas e a natureza, do que nas causas que geram os problemas vivenciados e que constituem, portanto, um dos pontos centrais de problematização e intervenção (Auler, \& Delizoicov, 2001). Assim, ao tecermos críticas apenas aos produtos da CT e às pessoas que fazem uso desses produtos, podemos estar deixando intocável o cerne dos problemas (o processo de produção da CT) e realizando apenas modificações pontuais na realidade, que ao encobrir questões centrais relacionadas à atual forma de sociabilidade dominante, podem reforçar a conservação das estruturas sociais, contribuindo muito pouco para transformá-las.

b) A CT não promove o bem-estar social: nessa categoria os licenciandos compreendem que a CT não consegue promover o bem-estar social, visto que a população é que tem potencial para isso, conforme extratos a seguir:

A CT não leva ao bem-estar social, porque quem é capaz de fazer isso mesmo é o ser humano na intenção do que ele quer fazer a partir disso. Porque de acordo com o que está sendo feito já poderia ter acontecido isso, não tinha mais fome, não tinha mais esse monte de coisa que, sabe que é bem rico o mundo (LQ4).

Eu acredito que no mundo capitalista não, porque hoje nós temos diversas técnicas, a exemplo de produção. Então é veiculado na mídia, por exemplo, que nós temos hoje a produção de alimentos superior a necessidade de planeta, como um todo, a produção do planeta da necessidade do próprio planeta, mas a gente ainda vê casos de fome. Então não é só ter aquela tecnologia, entendeu, a forma, mecanismo para, mas a 
utilização dele (LQ1).

Percebe-se nas falas que os licenciandos não endossam o mito de que a Ciência é capaz de resolver todos os problemas da humanidade, ao passo que evidenciam problemas atuais ainda não solucionados, mesmo com o desenvolvimento intenso da CT. Eles compreendem que a população é capaz de promover o bem-estar social, por meio de um melhor gerenciamento e distribuição dos produtos da CT, mas não evidenciam quem são as pessoas responsáveis ou que deveriam ser responsáveis pela produção científica e tecnológica ou mesmo quem estaria envolvido no processo de logística dos produtos gerados, se a população de forma geral ou alguns grupos específicos. Ademais, caberia ainda elucidar se os produtos produzidos e distribuídos foram pensados com a população que vai consumi-los, se são direcionados à solução de problemas sociais ou se, pelo contrário, estão contribuindo para o agravamento da crise socioambiental.

Na fala de LQ1 a discussão acerca da fome que assola o mundo, vem sendo relacionada à base material capitalista em que se fundam as sociedades, em que o desenvolvimento cada vez maior da CT não seria suficiente para superar esse problema social, considerando a forma de sociabilidade contemporânea. A esse respeito, Auler (2002) afirma que é um equívoco pensar que CT necessariamente conduzem ao bemestar social ou que foram criadas para solucionar problemas sociais. $\mathrm{O}$ autor entende que "nem Ciência, nem Tecnologia são alavancas para a mudança que afetam sempre, no melhor sentido, aquilo que transformam" (Auler, 2002, p. 106). Em relação ao problema da fome e da má distribuição dos alimentos no planeta, destacado pelos licenciandos, o autor ressalta que CT são fundamentais apenas no campo da produção, não estando diretamente ligadas a mecanismos que garantam a distribuição dos alimentos produzidos e, portanto, outras dimensões devem ser consideradas.

c) A CT pode salvar a humanidade se for redirecionada: o licenciando LQ5 compreende que o desenvolvimento científico e tecnológico pode promover o bemestar social, se o rumo das atividades for redirecionado de forma que não prejudique o Meio Ambiente (natural), conforme a fala a seguir:

Pode desde que ela [CT] seja realmente pensada na questão bem centrada, na questão ambiental, porque do jeito que os projetos vêm sendo feitos não [...]. É preciso que haja realmente um entendimento das questões ambientais para que esse desenvolvimento não seja prejudicial ao meio ambiente e favoreça esse negócio que fala no final do bem-estar social [...] (LQ5).

Para o licenciando é necessário um redirecionamento dos projetos da CT, pois as atividades atuais têm causado danos ambientais. Para que isso não ocorra, o licenciando defende que a CT seja concebida de maneira a considerar a questão ambiental, ou seja, para ele a CT deve ser construída tomando como ponto central o Meio Ambiente, a compreensão sobre esse meio, para que todos possam viver bem em sociedade. Esse discurso, embora ainda conserve marcas de um Meio Ambiente reduzido à natureza que sofre os impactos do desenvolvimento, se aproxima um pouco do que defende Amaral (2001) que toma o Meio Ambiente como o eixo gerador, articulador e integrador das 
ações desenvolvidas. Nessa concepção, esse meio seria mais do que o ponto de partida, porque assume o papel e a função de eixo estruturante, servindo como a dimensão central, multidimensional e totalizante das relações sociais.

Nessa perspectiva, Roso (2017) compreende que para se promover uma transformação social, é necessário se construir outro modelo de CT. Assim, o autor defende a construção de tecnologias sociais, isto é, tecnologias voltadas para o contexto local, para o atendimento das necessidades das pessoas historicamente excluídas, por entender que as tecnologias convencionais estão vinculadas aos pressupostos capitalistas, à lógica de mercado. Auler e Delizoicov (2015) e Strieder (2012) também defendem a necessidade de adequações sociais das tecnologias às demandas sociais, para que sejam pensadas e desenvolvidas de maneira a considerar as necessidades da sociedade e não para legitimar valores e visões de mundo descontextualizados e, portanto, externos à realidade vivenciada pelos sujeitos.

Essas são, sem dúvidas, algumas possibilidades que podem tornar viável a ideia defendida por LQ5, na medida em que, ao romper com discursos neoliberais sustentados no mito da neutralidade científica sob a ótica desenvolvimentista, defende a necessidade de que a CT não sirva a valores e ideologias particulares que foram tornados universais, mas às necessidades, demandas e perspectivas latentes da população que deve assumir uma relação sustentável com a natureza.

\section{Conclusões e Implicações}

O objetivo do presente estudo foi investigar as concepções de licenciandos em Química sobre as relações entre Meio Ambiente, Ciência, Tecnologia e Sociedade no sentido de subsidiar processos formativos a serem desenvolvidos no contexto do ensino de Ciências. Os licenciandos, em geral, apresentam uma visão otimista acerca das implicações sociais da CT e do papel das pessoas no encaminhamento e resolução dos problemas sociais, ao passo que se afastam de visões fatalistas que desconsideram a possibilidade de melhoria do atual estado em que se encontra a humanidade. Apesar de não serem pessimistas, ainda apresentam respostas pouco elaboradas sobre as situações apresentadas, visto que deixam de explorar de maneira mais aprofundada as relações internas e externas entre as dimensões da Ciência, Tecnologia, Sociedade e Meio Ambiente e as implicações dessas discussões numa conjuntura social mais ampla. Por exemplo, embora em alguns momentos defendam a participação social na definição dos rumos da Ciência, não apresentam as possíveis maneiras como as pessoas poderiam participar ou intervir e se isso ocorreria no momento atual em que vivemos ou em condições diferentes das que temos hoje.

A percepção mais focalista da atividade científico-tecnológica e suas relações com a Sociedade e a Natureza se expressa mais claramente quando os licenciandos, ao tratarem sobre as situações apresentadas, focam suas análises apenas no processo de pós-produção da CT, desconsiderando ou não reconhecendo a totalidade das múltiplas determinações que envolvem a construção da CT. Assim, consideram apenas o momento 
da utilização dos produtos, em que para as pessoas caberia, após estarem informadas sobre os efeitos negativos da Ciência, reduzir o consumo dos produtos gerados na etapa final do processo. A intenção da dinâmica estrutural dominante da Sociedade é justamente essa: encobrir ou ocultar a maneira como ocorre a construção social e historicamente determinada da Ciência; os interesses que estão em jogo, os favorecimentos, os possíveis erros cometidos e, ao mesmo tempo, retirar a possibilidade de que essa construção seja questionada, o que colocaria em xeque sua pretensa capacidade de oferecer respostas seguras e dignas de credibilidade por parte das pessoas como vem sempre ocorrendo nos anais da história.

Percebemos também que existem concepções variadas a respeito da maneira como as relações CTS são estabelecidas por parte de cada sujeito, especialmente no que tange a (não) neutralidade da CT. Essa variedade de posicionamentos aparece, por exemplo, quando os sujeitos expressam a compreensão que possuem sobre a (in) conciliação entre conservação e desenvolvimento, quase sempre ligada à uma concepção de Meio Ambiente próxima de natureza impactada, em que se ressalta a dimensão dos problemas ambientais causados pela atividade científico-tecnológica aos ecossistemas naturais. Além de diferentes, essas concepções que variam de um indivíduo para o outro e num mesmo indivíduo, muitas vezes, mostram-se contraditórias. A ambiguidade nas respostas dos estudantes sobre questões que envolvem a CT parece se acentuar na medida em que avançamos de um tema social para outro, o que nos leva a afirmar que as situações problemáticas e/ou controversas apresentadas funcionam como um mecanismo capaz de acionar diferentes respostas e posicionamentos.

Essas diferentes respostas dos licenciandos para as situações propostas apresentam-se sob a forma de discursos que, quando não se complementam, se anulam completamente e em última instância como diria Bourdieu (1996), constituem reflexos de contradições mais amplas presentes nas estruturas sociais, que ao serem internalizadas nos indivíduos, condicionam suas ações e as maneiras como compreendem a realidade da qual fazem parte. Esse poderia ser o caso dos licenciandos, em alguns momentos, endossarem uma perspectiva neutra para a CT, e em outros negarem essa suposta neutralidade, haja vista que a tendência positivista da Ciência ainda permanece sendo reafirmada na formação de professores de Ciências.

Os licenciandos não discutem sobre a realidade, que se mostra ainda para eles indecifrável/inacessível. Eles negligenciam ou não percebem os mecanismos, interesses e ideologias que estão em jogo no discurso dos especialistas e das pessoas em geral. Projetam-se para o futuro falando de uma realidade possível, mas que no momento ainda não existe. Tal qual proposições soltas ao espaço, sem considerar a lógica de produção e reprodução capitalista na contemporaneidade, as falas dos licenciandos, em sua maioria, perdem o sentido que poderiam adquirir num contexto determinado e historicamente situado. Considerando as condições existenciais postas pela sociedade capitalista e suas repercussões no âmbito das relações sociais, ambientais e políticas, qualquer discussão que não coloque em pauta essa forma de sociabilidade dominante no 
mundo, se afasta da realidade objetiva e corre o risco de tornar-se um discurso vazio. Tal discurso, ao invés de servir para a transformação crítica da realidade, pode contribuir para reproduzir as relações desiguais numa sociedade de classes.

Diante dessa situação, compreendemos que as discussões sobre CTS parecem não ter sido abordadas, de forma aprofundada, durante a formação inicial dos sujeitos aqui investigados, constituindo-se um dado a ser considerado posteriormente em pesquisas a serem desenvolvidas na área. Além disso, relacionar Meio Ambiente, Ciência, Tecnologia e Sociedade ainda é um desafio no âmbito da formação de professores de Ciências, mesmo que já existam materiais didáticos, cursos e pesquisas desenvolvidas em Educação em Ciências desde a década de 1990. Dentre os desafios a serem enfrentados pela agenda de pesquisa em Educação em Ciências, este trabalho contribui para o entendimento de que a vinculação entre Meio Ambiente e as demais dimensões presentes na tríade CTS, talvez se constitua numa necessidade cada vez mais latente a ser colocada como uma demanda de investigação, principalmente quando verificamos que pesquisadores da área de Educação Ambiental, historicamente, pouco se comunicaram com pesquisadores da área de Educação CTS, interface que pode colaborar para enriquecer científica e politicamente o campo da Educação em Ciências no contexto atual de emergência planetária (Luz, 2019).

Outra constatação importante se refere ao direcionamento dado pelos pesquisadores durante o levantamento de concepções dos sujeitos na pesquisa em Educação em Ciências. Neste trabalho, percebemos que utilizar situações polêmicas e/ ou controversas durante as entrevistas, ao invés de perguntas conceituais diretas, permite não só levantar saberes prévios, mas também disposições para a prática intrinsecamente contraditórias. Aliás, identificar e trabalhar essas contradições no contexto capitalista atual, talvez se constitua numa condição imprescindível para proliferar sucessivas sínteses superadoras dos problemas cotidianamente enfrentados.

Assim, fica evidente a necessidade de problematizar as relações CTS no processo de formação inicial de professores, uma vez que o presente estudo aponta compreensões pouco elaboradas e confusas a esse respeito. Para alcançar resultados mais perenes e significativos é necessário que os cursos de formação inicial em Ciências repensem seus currículos e os elaborem de forma a incorporar elementos e pressupostos da Educação CTS, pois diante de um mundo científico e tecnológico é importante que os professores acompanhem tais mudanças que influenciam diretamente no processo educacional.

Assumir uma práxis educativa em Ciências pautada nos pressupostos CTS e da Educação Ambiental Crítica, pressupõe se colocar num movimento de embate contra o saber curricular cristalizado e práticas de ensino habituais; contra a imposição de um "caminho único" em educação, combatendo o mito da existência de uma verdade absoluta, desprovida de ideologias e vieses. Pressupõe também um embate intencional contra as bases institucionais que buscam conservar seus mecanismos de dominação da sociedade, ao passo que investimos esforços conjuntos para criar possibilidades reais de enfrentamento dos problemas cotidianos numa perspectiva consciente, política, 
reflexiva e crítica de transformação social.

\section{Agradecimentos}

Agradecemos aos estudantes de Licenciatura em Química da Universidade Estadual de Santa Cruz, localizada no município de Ilhéus/BA, pelas entrevistas concedidas; à Fundação de Amparo à Pesquisa do Estado da Bahia (FAPESB) e à Coordenação de Aperfeiçoamento de Pessoal de Nível Superior (CAPES) pelo apoio financeiro na forma de bolsas de mestrado e doutorado.

\section{Referências}

Aikenhead, G. (1994). What is STS science teaching? In J. Solomon, \& G. Aikenhead (Eds.). STS Education: international perspectives on reform. New York: Teachers College Press, 47-59.

Amaral, I. A. (2001). Educação Ambiental e Ensino de Ciências: uma história de controvérsias. Proposições, 12(1), 73-93. Recuperado de: https://perioquero dicos.sbu. unicamp.br/ojs/index.php/proposic/article/view/8644012

Auler, D. (2002). Interações entre ciência-tecnologia-sociedade no contexto da formação de professores de ciências. (Tese de Doutorado). UFSC, Florianópolis, Santa Catarina. Recuperado de: https://repositorio.ufsc.br/handle/123456789/82610

Auler, D. (2018). Cuidado! Um cavalo viciado tende a voltar para o mesmo lugar. $1^{\text {a }}$ ed. Curitiba: Appris.

Auler, D., \& Delizoicov, D. (2001). Alfabetização científico-tecnológica para quê? Ensaio - Pesquisa em Educação em Ciências, 3(2), 105-115. https://doi.org/10.1590/198321172001030203

Auler, D., \& Delizoicov, D. (2006). Ciência-Tecnologia-Sociedade: relações estabelecidas por professores de ciências. Revista Electrónica de Enseñanza de las Ciencias, 5, 337-35. Recuperado de: http://reec.uvigo.es/volumenes/volumen5/ART8_Vol5_N2.pdf

Auler, D., \& Delizoicov, D. (2015). Investigação de temas CTS no contexto do pensamento latino-americano. Linhas Críticas. 21(45), 275-296. Recuperado de: http://periodicos. unb.br/index.php/linhascriticas/article/view/16728

Bourdieu, P. (1996). Razões práticas sobre a teoria da ação. Tradução Mariza Corrêa Campinas, São Paulo: Papirus. Recuperado de: https://auladesociologia.files.wordpress. com/2012/04/bourdieu-pierre-razc3b5esprc3a1ticas.pdf

Deconto, D. C. S., Cavalcanti, C. J. H., \& Ostermann, F. (2016). A perspectiva Ciência, Tecnologia e Sociedade na formação inicial de professores de Física: estudando concepções a partir de uma análise Bakhtiniana. Alexandria - Revista de Educação em. Ciência e Tecnologia, 9(2), 87-119. https://doi.org/10.5007/1982-5153.2016v9n2p87 
Delizoicov, D. (2004). Pesquisa em ensino de ciências como ciências humanas aplicadas. Caderno Brasileiro de Ensino de Física, 21 (2), 145-175. https://doi.org/10.5007/\%25x

Delizoicov, D., \& Auler, D. (2011). Ciência, Tecnologia e Formação social do espaço: questões sobre a não-neutralidade. Alexandria - Revista de Educação em. Ciência e Tecnologia, 4 (2), 247-273. https://doi.org/10.5007/\%25x

Firme, R. N., \& Amaral, E. M. R. (2008). Concepções de professores de Química sobre Ciência, Tecnologia, Sociedade e suas inter-relações: um estudo preliminar para o desenvolvimento de abordagens CTS em sala de aula. Ciência \& Educação. 14(2), 251269. http://dx.doi.org/10.1590/S1516-73132008000200005

Fourez, G. (1995). A construção das ciências: introdução à filosofia e à ética das ciências. São Paulo: Editora da Universidade Estadual Paulista.

Freire, P. (1987). Pedagogia do oprimido. (17 a ed.). Rio de Janeiro: Paz e Terra.

Freitas, L. M., \& Ghedin, E. (2015). Pesquisas sobre estado da arte em CTS: análise comparativa com a produção em periódicos nacionais. Alexandria - Revista de Educação em Ciência e Tecnologia, 8(3), 3-25. https://doi.org/10.5007/1982-5153.2015v8n3p3

Gil-Pérez, D., Montoro I. F., Alís J. C., Cachapuz, A., \& Praia, J. (2001). Para uma imagem não deformada do trabalho científico. Ciência \& Educação, 7(2), 125-153. Recuperado de: http://www.scielo.br/pdf/ciedu/v7n2/01.pdf

Kist, C. P., \& Ferraz, D. F. (2010). Compreensão de professores de biologia sobre as interações entre ciência, tecnologia e sociedade. Revista Brasileira de Pesquisa em Educação em Ciências, 10(1). Recuperado de: https://seer.ufmg.br/index.php/rbpec/ article/view/2187/1587

Latour, B., \& Woolgar, S. (1997). A vida de laboratório: a produção dos fatos científicos. Rio de Janeiro: Relume Dumará. Recuperado de: https://pedropeixotoferreira.files. wordpress.com/2011/02/latourewoolgar_1997_a-vida-de-laboratorio-e28093-aproducao-dos-fatos-cientificos_book.pdf

Lessa, S., \& Tonet, I. (2008). Introdução à filosofia de Marx. São Paulo: Expressão Popular. Recuperado de: http://sergiolessa.com.br/uploads/7/1/3/3/71338853/introdufilomarx. pdf

Luz, R., Prudêncio, C. A. V., \& Caiafa, A. N. (2018). Contribuições da Educação Ambiental Crítica para o processo de ensino e aprendizagem em Ciências visando à formação cidadã. Investigações em ensino de Ciências (online), 23 (3), p. 60-81. https:// doi.org/10.22600/1518-8795.ienci2018v23n3p60

Luz, R., Araújo-Queiroz, M. B., Prudêncio, C. A. V. (2019). CTS ou CTSA: o que (não) dizem as pesquisas sobre Educação Ambiental e Meio Ambiente? Alexandria (UFSC), 12(1), p. 31-54. http://dx.doi.org/10.5007/1982-5153.2019v12n1p31 
Luz, R., Santana, U. S., Monteiro, A. S. S., Santos, S. F. C., Cirqueira, J. S., Almeida, R. (2017). Concepções ambientais dos estudantes do curso de Licenciatura em Biologia da UFRB. Educação Ambiental em Ação, 60(1), p. 1-11. Recuperado de: http://www. revistaea.org/artigo.php?idartigo $=2738$

Luz, R. S. (2016). Contribuições da Educação Ambiental no processo de ensino e aprendizagem em ciências para a formação cidadã do estudante. Trabalho de Conclusão de Curso (Licenciatura em Biologia) - Universidade Federal do Recôncavo da Bahia UFRB, Cruz das Almas, Bahia. Recuperado de: http://www.repositoriodigital.ufrb.edu. br/bitstream/123456789/1182/1/Monografia\%20Rodrigo\%20Silva.pdf

MEC, (2000). Ministério da Educação. Parâmetros Curriculares Nacionais (Ensino Médio). Brasília: Ministério da Educação. Recuperado de: http://portal.mec.gov.br/seb/ arquivos/pdf/blegais.pdf

Morais, R., \& Galiazzi, M. C. (2011). Análise textual discursiva. (2ª ed.) Ijuí: Unijuí.

Prudêncio, C. A. V. (2013). Perspectiva CTS em estágios curriculares em espaços de divulgação científica: contributos para a formação inicial de professores de Ciências e Biologia. Tese (Doutorado) - São Carlos, UFScar. Recuperado de: https://repositorio. ufscar.br/handle/ufscar/2332? show=full

Reis, P., Rodrigues, S., \& Santos, F. (2006). Concepções sobre cientistas em aluno do $1^{\circ}$ ciclo do ensino básico: poções, máquinas, monstros, invenções e outras coisas malucas. Revista Eletronica de Enseñanza de las Ciencias, 5(1), 57-73. Recuperado de: http:// repositorio.ul.pt/handle/10451/4618

Roso, C. C. (2017). Transformações na educação CTS: uma proposta a partir do conceito de Tecnologia Social. (Tese de Doutorado). UFSC, Florianópolis, Santa Catarina. Recuperado de: https://repositorio.ufsc.br/handle/123456789/187060

Roso, C. C., \& Auler, D. (2016). A participação na construção do currículo: Práticas Educativas Vinculadas ao movimento CTS. Ciência \& Educação, 22(2), 371-389. http:// dx.doi.org/10.1590/1516-731320160020007

Santos, W. L. P. (2007). Contextualização no Ensino de Ciências por meio de temas CTS em uma perspectiva crítica. Ciência \& Ensino, 1(esp.). Recuperado de: http://www. cienciamao.usp.br/tudo/exibir.php?midia=rcen\&cod=_contextualizacaonoensino

Santos, W. L. P., \& Schnetzler, R. P. (2010). Educação em Química: compromisso com a cidadania. ( $4^{\mathrm{a}}$ ed.) Ijuí: Unijuí.

Santos, W. L. P, \& Mortimer, E. F. (2002). Uma análise de pressupostos teóricos da Abordagem CTS (Ciência-Tecnologia-Sociedade) no contexto da Educação Brasileira. Ensaio - Pesquisa em Educação em Ciências, 2(2), 110-132. http://dx.doi. org/10.1590/1983-21172000020202 
Silva, A. T. R. (2015). A conservação da biodiversidade entre os saberes da tradição e a ciência. Estudos Avançados. 29(83), 233-259. http://dx.doi.org/10.1590/S010340142015000100012

Strieder, R. B. (2012). Abordagens CTS na educação científica no Brasil: Sentidos e perspectivas. (Tese de Doutorado). USP, São Paulo. Recuperado de: http://www.teses. usp.br/teses/disponiveis/81/81131/tde-13062012-112417/pt-br.php

Strieder, R. B., Bravo-Torija, B., \& Gil-Quilez, M. J. (2017) Ciencia-tecnología sociedad: ¿Qué estamos haciendo en el ámbito de la investigación en educación em ciencias? Enseñanza de las Ciencias, 35(3), 29-49. Recuperado de: https://www.raco.cat/index. php/Ensenanza/article/view/32920

Strieder, R. B., \& Kawamura, M. R. D. (2017). Educação CTS: Parâmetros e Propósitos Brasileiros. Alexandria - Revista de Educação em Ciência e Tecnologia, 10(1), 27-56. https://doi.org/10.5007/1982-5153.2017v10n1p27 
Rodrigo Luz

${ }^{\circledR}$ https://orcid.org/0000-0001-5711-1447 Universidade Federal da Bahia Faculdade de Educação Salvador, Bahia, Brasil rodrigoluz_saj@live.com

\section{Eliane dos Santos Almeida}

[1] https://orcid.org/0000-0002-8798-051X Universidade de Brasília Instituto de Química Brasília, Distrito Federal, Brasil almeida-eliane@hotmail.com

Elisangela Silva do Nascimento

[(] https://orcid.org/0000-0002-5512-1059

Universidade Estadual de Santa Cruz Departamento de Ciências Exatas e Tecnológicas Ilhéus, Bahia, Brasil elyysantos2010_@hotmail.com

\section{Christiana Andréa Vianna Prudêncio}

[1] https://orcid.org/0000-0002-4571-2090

Universidade Estadual de Santa Cruz Departamento de Ciências Biológicas Ilhéus, Bahia, Brasil cavprudencio@uesc.br

Submetido em 04 de janeiro de 2019 Aceito em 09 de setembro de 2019 Publicado em 27 de outubro de 2019 